\title{
Computerised intraocular lens calculation: clinical results and predictability
}

\author{
THOMAS OLSEN, CARL UGGERHØJ ANDERSEN, AND \\ HANS-JØRGEN PLESNER \\ From the Department of Ophthalmology, University of Aarhus, Aarhus Kommunehospital, DK-8000 \\ Aarhus C, Denmark
}

SUMMARY The predictability of a theoretical, computer-assisted IOL calculation method and of the Sanders-Retzlaff-Kraff (SRK) method was evaluated from pre- and postoperative biometry in 110 cataractous patients subjected to a routine IOL calculation. With the theoretical method and the preoperative data the refraction was on the average $0.72 \mathrm{D}(\mathrm{SD} 0.78$ ) more myopic than expected, an error which could be corrected for by (1) substituting the assumed postoperative chamber depth by the actual mean value and (2) adding $0 \cdot 16 \mathrm{~mm}$ to the preoperative axial length. With the postoperative data the error was 0.05 D (SD 0.78) (p>0.05). By the SRK method the refraction was $0.15 \mathrm{D}$ (SD 0.71 ) and $0.37 \mathrm{D}$ (SD 0.69) more hyperopic than expected with the preand the postoperative data respectively. These offset errors could be corrected for in either case by adjusting the assumed A constant in the SRK formula. With appropriate empirical corrections for offset errors the theoretical and the SRK method were similar in accuracy, that is, about $82 \%$ of the predictions within $\pm 1 \mathrm{D}, 99 \%$ within $\pm 2 \mathrm{D}$, and $100 \%$ within $\pm 3 \mathrm{D}$ error. The variation in postoperative refraction after computerised IOL calculation was about one-third of the variation previously seen after implantation of standard power IOL.

The calculation of intraocular lens (IOL) power has been possible since the introduction of accurate ultrasonic equipment for the measurement of the axial length of the eye. The first formulae were theoretical and derived from laws of paraxial imagery by means of various sets of assumptions. ${ }^{1-3}$ The more recent empirical formulae represent a different approach based on a statistical regression analysis of the actual refraction observed in a large number of operated patients. ${ }^{47}$ There seems to be no general agreement on which approach is the more accurate,,$^{8-10}$ and opinions still differ on the importance of doing a routine IOL calculation. ${ }^{11-14}$

We have recently developed a computer assisted theoretical approach to IOL calculation using assumption free formulae within the theory of Gaussian optics. This method represents an improvement over current theoretical methods in the calculation of corneal power and in dealing with the principal planes. ${ }^{15}$ In a previous study this method was found to be more accurate than the Sanders-

Correspondence to Dr Thomas Olsen, University Eye Clinic, Aarhus Kommunehospital, DK-8000 Aarhus C, Denmark.
Retzlaff-Kraff (SRK) formula in the prediction of ametropia. ${ }^{16}$

In this investigation we report the results after routine IOL calculation aiming for about $-1 \mathrm{D}$ postoperatively. In addition, the prediction accuracy of the theoretical and the SRK method is evaluated on both the pre- and the postoperative data.

\section{Material and methods}

One hundred and ten patients, 43 males and 67 females, in the age range 57-94 years, mean 75.4 (SD 8.0) years, were studied. They constituted a consecutive series of patients undergoing routine cataract extraction on an outpatient basis from February to June 1986. During the study it was a routine procedure to do an intracapsular cataract extraction with the implantation of an anterior chamber lens (Intermedics 44B, a planoconvex flexible loop lens) in patients with no contraindications against IOL implantation, with no history of retinal detachment, with no previous cystoid maculopathy, and with no excessive myopia (more 
than 6 dioptres axial myopia). The operative procedure was cryoextraction after corneal incision and zonulysis.

Before surgery the axial length and the anterior chamber depth were measured with ultrasonic Ascan (O cuscan, Sonometrics) using a $10 \mathrm{MHz}$ solid transducer probe and an electronic reading system. The velocity of ultrasound was assumed to be 1550 $\mathrm{m} / \mathrm{s}$ for the whole phakic eye and $1532 \mathrm{~m} / \mathrm{s}$ for the anterior chamber (from corneal surface to lens surface). ${ }^{17}$ The corneal curvature was measured in two meridians with either a manual (Zeiss) keratometer (one-third of the cases) or with an automatic keratometer (Nidek KM-800) (two-thirds of the cases). Both keratometers were calibrated and found to give identical results.

The theoretical prediction of IOL power, the biological lens power, and the ocular magnification were calculated by a theoretical computer assisted method as previously described. ${ }^{15}$ Preoperatively, the postoperative chamber depth was assumed to be $3.0 \mathrm{~mm}$ in all cases. The IOL power was selected aiming for about $-1 \mathrm{D}$ postoperatively with tolerable aniseikonia. A maximum aniseikonia of $10 \%$ was accepted, depending on the vision of the fellow eye. For the present study the computer program was integrated with a database and written in a compiled version of BASIC (TURBO BASIC by Borland International) and run on an IBM AT personal computer.

The $\mathrm{SRK}^{7}$ prediction of postoperative refraction was calculated as:

$$
\mathrm{R}=(\mathrm{P}-\mathrm{I}) / 1 \cdot 5 \text {, }
$$

where $R$ is refraction, $I$ is power of implant, and $P$ is emmetropia yielding power of IOL, calculated as:

$$
\mathrm{P}=\mathrm{A}-2.5 \mathrm{Ax}-0.9 \mathrm{Fc} \text {, }
$$

where $\mathrm{Ax}$ is axial length and $\mathrm{Fc}$ is corneal power calculated on the assumption of a corneal refractive index of 1.3375 . The $A$ constant was assumed to be $114 \cdot 8$, as stated by the manufacturer.

Six months after surgery the refraction was recorded as the correction giving the best Snellen visual acuity at $6 \mathrm{~m}$. All refractions were calculated as spherical equivalents. To be accepted for the study a final visual acuity of $20 / 40$ or better was required. Again, the corneal curvature, the anterior chamber depth, and the axial length were measured. The axial length was corrected for the presence of the IOL by assuming a velocity of ultrasound in polymethyl methacrylate (PMMA) of $2981 \mathrm{~m} / \mathrm{s} .{ }^{18}$ With the present average IOL thickness of $0.9 \mathrm{~mm}$ this was the equivalent of adding $0.4 \mathrm{~mm}$ to the reading obtained with the velocity set at $1532 \mathrm{~m} / \mathrm{s}$.
Table 1 Pre-and postoperative data of 110 patients with computerised calculation of IOL power; means with SD in parentheses

\begin{tabular}{lclll}
\hline $\begin{array}{l}\text { Refraction } \\
(D)\end{array}$ & $\begin{array}{l}\text { Corneal power } \\
(D)\end{array}$ & $\begin{array}{l}\text { Lens power } \\
(D)\end{array}$ & $\begin{array}{l}\text { Axial length } \\
(\text { mm })\end{array}$ \\
\hline Pre- & $0 \cdot 16$ & 42.99 & 23.08 & $23 \cdot 16$ \\
op. & $(2 \cdot 50)$ & $(1.51)$ & $(3.26)$ & $(1.02)$ \\
Post- & -1.59 & 42.98 & $20 \cdot 11$ & 23.31 \\
op. & $(0.75)$ & $(1.53)$ & $(2.52)$ & $(1.04)$ \\
\hline
\end{tabular}

methods, and the results were generally stated as arithmetical means \pm one standard deviation (SD). For comparison of paired data Student's paired $t$ test was applied. ${ }^{19}$

\section{Results}

The pre- and the postoperative clinical data appear in Table 1 . The mean refraction after surgery (SD) was $-1.59 \mathrm{D}(0.75)$, range -3.1 to $+1.1 \mathrm{D}$. This was produced by the implantation of IOL powers ranging from 12.5 to $28 \mathrm{D}$ (mean $20 \cdot 11 \mathrm{D}$ ). The mean difference between the biological and the implant lens power was $-2.0 \mathrm{D}(3.46)$. The mean corneal power (spherical equivalent) did not change significantly after the operation, the mean change being $-0.01 \mathrm{D}(0.38)$. The axial length, however, was found to increase by $0.15 \mathrm{~mm}(0.24)(\mathrm{p}<0.001)$.

The increase in ocular magnification (aniseikonia) with correction was on the average $2 \%$ (SD $4 \cdot 2$ ), with a range of -7 to $19 \%$. The patients in whom an increase of more than $10 \%$ was allowed were myopes with a fellow eye of poor vision to preclude binocularity.

The error of prediction with the theoretical and the SRK method using pre- and postoperative sets of data have been summarised in Table 2. For the

Table 2 The refractive prediction error in 110 patients with computerised IOL calculation. Method $A=$ theoretical method with uncorrected preoperative data. Method $B=$ theoretical method and preoperative data, substituting the assumed postoperative chamber depth by the actual value of $2.82 \mathrm{~mm}$. Method $C=$ theoretical method with postoperative data. Method $D=S R K$ method with preoperative data. Method E $=S R K$ method with postoperative data. Means with $S D$ in parentheses

\begin{tabular}{lll}
\hline Method & Error $(D)$ & Range $(D)$ \\
\hline A & $-0.72 *(0.78)$ & $-2.70(2.26)$ \\
B & $-0.45^{*}(0.76)$ & $-2.33(2.36)$ \\
C & $+0.05 \ddagger(0.78)$ & $-1.92(1.75)$ \\
D & $+0.15 \dagger(0.71)$ & $-1.73(2.45)$ \\
E & $+0.37 *(0.69)$ & $-1.33(2.42)$ \\
\hline
\end{tabular}

*Different from zero $(p<0 \cdot 001)$. $†$ Different from zero $(p<0 \cdot 05)$. $\ddagger$ Not significant $(\mathrm{p}>0.05)$. 
theoretical method the error was $-0.72 \mathrm{D}(0.78)$ when the preoperative data were used in the calculations. This mean error was significantly different from zero $(p<0 \cdot 01)$. Some of this error was due to an overestimation of the postoperative chamber depth, the actual value of which was found to be $2.82 \mathrm{~mm}$ $(0 \cdot 29)$. When this value, rather than the presumed value of $3.00 \mathrm{~mm}$ was used in all calculations, the mean prediction error reduced to $-0.45 \mathrm{D}(0.75)$. The residual error of $0.45 \mathrm{D}$ more myopic than expected could be corrected for by adding $0.16 \mathrm{~mm}$ to the preoperative axial length. When the postoperative data were used in the calculations, the error was $-0 \cdot 05 \mathrm{D}(0 \cdot 78)$, which was not significantly different from zero $(\mathrm{p}>0 \cdot 05)$.

For the SRK method the preoperative error of prediction was $+0.15 \mathrm{D}(0 \cdot 71)$. This error was significantly different from zero $(\mathrm{p}<0 \cdot 05)$, and could be corrected for by adding $0.22 \mathrm{D}$ to the A constant or, alternatively, by subtracting $0.09 \mathrm{~mm}$ from the axial length. With the postoperative data the error was $+0.37 \mathrm{D}(0.71)(\mathrm{p}<0.01)$. The mean error could be corrected for by adding $0.55 \mathrm{D}$ to the A constant or by subtracting $0.22 \mathrm{~mm}$ from the axial length.

With the appropriate empirical corrections for observed offset errors, the predictability of the theoretical method was comparable in accuracy with that of the SRK method, as shown in Fig. 1. The observed variation around the mean value was not significantly different between the two methods ( $p>0.05$ by $F$ test). With either method about $82 \%$ of the predictions were within $\pm 1 \mathrm{D}, 99 \%$ within $\pm 2 \mathrm{D}$, and all within \pm 3 D error.

\section{Discussion}

Patients are generally satisfied with a postoperative refraction in the slightly myopic range. Without spectacles the patients enjoy comfortable distant vision, and many are able to read provided the astigmatism is not too large. The present study has shown that it is possible to aim for this refractive range by a routine calculation of IOL power. In Fig. 2 the present results have been compared with the variation observed after implantation of a standard power lens (data from previous study ${ }^{20}$ ). The narrowing of the postoperative range after computerised IOL calculation represents a reduction to one-third of the variation seen after standard power lens $(95 \%$ confidence interval of $3 \mathrm{D}$ versus $8.5 \mathrm{D}$ after standard power lens). Large refractive errors are hereby virtually avoided, and the beneficial effect of a routine IOL calculation is clearly demonstrated.

The sources of error in IOL calculation are manifold. Measurement errors will always be responsible for a random variation whichever method is used. By
Fig. 1 Error (in dioptres) of prediction of postoperative refraction in 110 patients with computerised IOL calculation. The predictions have been corrected for offset errors by adjusting the postoperative chamber depth and the axial length for the theoretical method, and by adjusting the $A$ constant for the SRK method. Solid columns = theoretical method, interrupted columns $=S R K$ method.

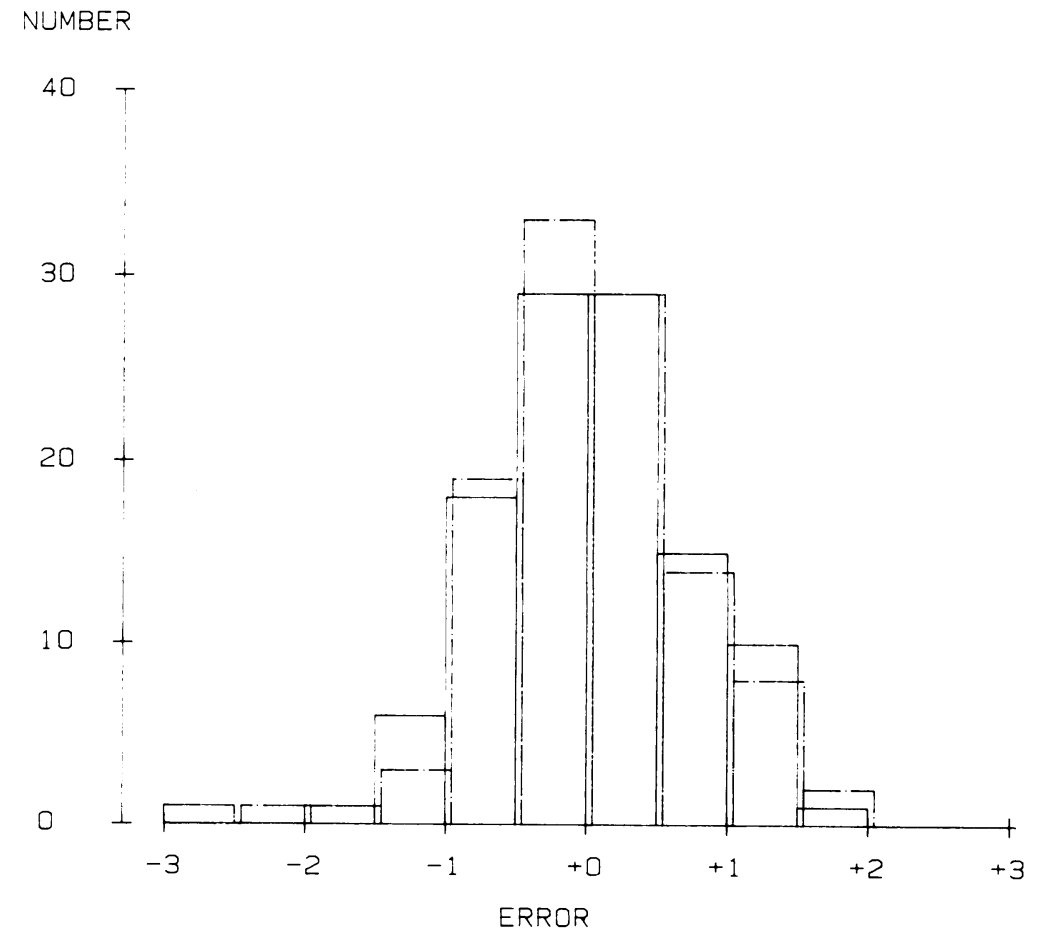




\section{NUMBER}

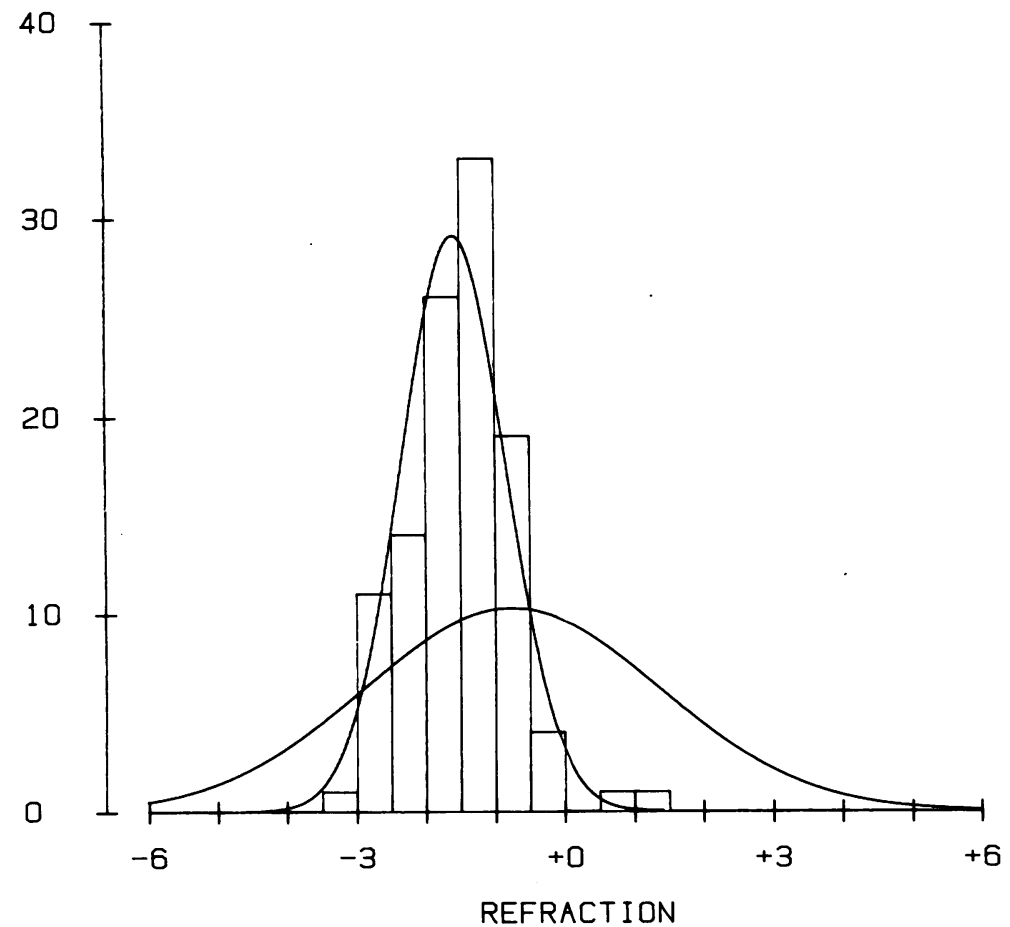

Fig. 2 The distribution of the postoperative refraction after routine $I O L$ calculation. The histogram was not significantly different from a normal distribution by $\chi^{2}$ test $(p>0.05)$. For comparison, the results after implantation of standard power IOL have been included (broader distribution).

analysing the systematic errors, however, it is possible to correct for offset errors which may show up in the theoretical as well as in the empirical method. For the theoretical method the accuracy can be improved by adjusting the postoperative chamber depth according to the value actually observed. ${ }^{10}$ No attempt was made in the present study to make an individual prediction of the postoperative chamber depth, though such methods have been described for another type of anterior chamber lens. ${ }^{21}$ It is possible that an improved prediction of the individual IOL position may further increase the accuracy of the theoretical method.

When the correction for actual mean postoperative chamber depth has been done, a residual error may remain, which may have different sources. An 'inborn error' of the theoretical approach is the small distance from the vitreoretinal surface to the sensory elements of the retina, which apparently calls for the addition of a small distance to the distance as measured by ultrasound. Many other errors exist, however, such as errors in calibration, the method of alignment, possible compression of the globe during measurement, density of the cataract, difference between keratometry and true corneal power, and optical aberrations of the eye, etc., all of which may make the distance measured by ultrasound differ from the axial length in the optical sense. It is difficult to make a-priori recommendations as to the magnitude of these errors and their possible correction. In the present study the residual error was the equivalent of $0.16 \mathrm{~mm}$ added to the preoperative axial length. For other systems, especially for other types of equipment for axial length measurements, it is possible that other corrections may be necessary. 22.3 This is how to 'personalise' the IOL calculation according to the theoretical approach.

When the postoperative data were used in the 'predictions', it was not necessary to use any axial length correction with the theoretical method. In view of the retinal thickness problem this may seem surprising, but because of the complexity of possible errors, as stated above, it is not certain that all corrections should be in the form of addition to the axial length. Along with the disappearance of the axial length correction an increase in the axial length was noted. Rather than representing a true enlargement of the globe after surgery, this apparent increase may indicate a higher velocity of ultrasound in the cataractous lens than previously assumed. This is in accordance with the findings in aphakic subjects. $^{24}$ 
The SRK approach may be adapted to the individual patient by adjusting the $\mathrm{A}$ constant in the regression formula. In this way any offset error may be corrected, but the variation round the mean remains unchanged. This is the equivalent of adjusting the average postoperative chamber depth and the axial length in the theoretical method. It is often stated that personalising the A constant accounts for differences in surgical technique and style of IOL. However, corrections are made for many other errors, such as calibration errors and differences in measuring technique. Because the axial length determination is probably the most vulnerable step in the IOL calculation, an alternative adjustment of the SRK approach is to correct the axial length by the amount of the empirically observed offset error. This would give as accurate results.

The present study has shown that there is no significant difference between the accuracy of the SRK and the theoretical approach when aiming for the near emmetropia region in normal cataractous patients. This result is in contrast to the results in ametropia, for which the theoretical method has been shown to be more accurate. ${ }^{16}$ It is not surprising that the SRK method works at its best for the refractive range for which it was derived. To improve the accuracy of the empirical method in the extreme range new classes of non-linear regression formulae have been described, which may work better for unusually long and short eyes. ${ }^{2526}$

This work was supported by the Danish Medical Research Council, grant no 12-5628, and in part by the Institute of Experimental Clinical Research, University of Aarhus.

\section{References}

1 Colenbrander MC. Calculation of the power of an iris clip lens for distant vision. Br J Ophthalmol 1973; 57: 735-40.

2 Binkhorst RD. Dioptrienzahl kunstlicher Augenlinsen. Klin Monatsbl Augenheilkd 1973; 362: 354-61.

3 Fyodorov SN, Galin MA, Linksz A. Calculation of the optical power of intraocular lenses. Invest Ophthalmol Vis Sci 1975; 14: 625-8.

4 Retzlaff J. A new intraocular lens calculation formula. $J A m$ Intraocul Implant Soc 1980; 6: 148-52.

5 Sanders DR, Kraff MC. Improvement of intraocular lens power calculation using empirical data. J Am Intraocul Implant Soc 1980; 6: 263-7.
6 Gills JP. Minimizing postoperative refractive error. Contact Intraocul Lens Med J 1980; 6: 56-9.

7 Sanders DR, Retzlaff J, Kraff M, et al. Comparison of the accuracy of the Binkhorst, Colenbrander, and SRK implant power predictions. J Am Intraocul Implant Soc 1981; 7: $337-40$.

8 Hillman JS. Intraocular lens power calculation - the selection of formula. Trans Ophthalmol Soc UK 1985; 104: 693-8.

9 Richards SC, Olsen RJ, Richards, WL, Brodstrin RS, Phillips NH. Clinical evaluation of six intraocular lens calculation formulas. J Am Intraocul Implant Soc 1985; 11: 153-8.

10 Holladay JT, Prager TC, Ruiz RS, Lewis JW, Rosenthal H. Improving the predictability of intraocular lens power calculations. Arch Ophthalmol 1986; 104: 539-41.

11 Thompson SM, Mohan-Roberts V. A comparison of postoperative results with and without intraocular lens power calculation. Br J Ophthalmol 1986; 70: 22-5.

12 Percival P. Lens power calculation-is it necessary? Trans Ophthalmol Soc UK 1983; 103: 577-9.

13 Olson RJ. Intraocular lens power calculations. Arch Ophthalmol 1987; 105: 1035-6.

14 Singh K, Sommer A. Intraocular lens power calculations: a practical evaluation in normal subjects at the Wilmer Institute. Arch Ophthalmol 1987; 105: 1046-50.

15 Olsen T. Theoretical approach to intraocular lens calculation using Gaussian optics. J Cataract Refract Surg 1987; 13: 141-5.

16 Olsen T. Theoretical, computer assisted prediction versus SRK prediction of postoperative refraction after IOL implantation. J Cataract Refract Surg 1987; 13: 146-50.

17 Jansson F, Kock E. Determination of the velocity of ultrasound in the human lens and vitreous. Acta Ophthalmol (Kbh) 1962; 40: 420-33.

18 Freudiger $\mathrm{H}$, Artaria L, Niesel P. Influence of intraocular lenses on ultrasound axial length measurement: In vitro and in vivo studies. J Am Intraocul Implant Soc 1984; 10: 29-34.

19 Armitage P. Statistical methods in medical research. London: Blackwell, 1977.

20 Olsen T. Pre- and postoperative refraction after implantation of standard power IOL. Br J Ophthalmol in press.

21 Olsen T. Prediction of intraocular lens position after cataract extraction. J Cataract Refract Surg 1986; 12: 376-9.

22 Shammas HJ. A comparison of immersion and contact techniques for axial length measurements. J Am Intraocul Implant Soc 1984; 10: 444-7.

23 Artaria LG. Messung der Bulbuslänge mit verschiedenen Ultraschall-Geräten. Klin Monatsbl Augenheilkd 1986; 188: $492-4$.

24 Olsen T. Theoretical vs empirical prediction of aphakic refraction. Arch Ophthalmol 1987; 105: 1042-5.

25 Thompson JT, Maumenee AE, Baker CC. A new posterior chamber intraocular lens formula for axial myopes. Ophthalmology 1984; 91: 484-8.

26 Donzis PB, Kastl PR, Gordon RA. An intraocular lens formula for short, normal and long eyes. CLAOJ 1985; 11: 95-8.

Accepted for publication 25 February 1988. 